\title{
Senior charge nurses' leadership behaviours in relation to hospital ward safety: a mixed method.
}

\author{
AGNEW, C. and FLIN, R.
}

2014 
AGNEW, C. and FLIN, R. 2014 International Journal of Nursing Studies, 51(5), 768-780.

\title{
Senior charge nurses' leadership behaviours in relation to hospital ward safety
}

\begin{abstract}
Background: High standards of quality and patient safety in hospital wards cannot be achieved without the active role of the nursing leaders that manage these units. Previous studies tended to focus on the leadership behaviours of nurses in relation to staff job satisfaction and other organizational outcomes. Less is known about the leadership skills of senior charge nurses that are effective for ensuring safety for patients and staff in their wards.
\end{abstract}

Objectives: The aim of the two studies was to identify the leadership behaviours of senior charge nurses that are a) typically used and, b) that relate to safety outcomes.

Methods: In study one, semi-structured interviews were conducted with 15 senior charge nurses at an acute NHS hospital. Transcribed interviews were coded using Yukl's Managerial Practices Survey (MPS) framework. In study two, self ratings of leadership (using the MPS) from 15 senior charge nurses ( $\mathrm{SCN})$ and upward ratings from 82 staff nurses reporting to them were used to investigate associations between SCNs' leadership behaviours and worker and patient-related safety outcomes.

Results: The interviews in study one demonstrated the relevance of the MPS leadership framework for nurses at hospital ward level. The SCNs mainly engaged in relations-oriented $(n=370,49 \%)$, and task-oriented $(n=342,45 \%)$ behaviours, with fewer change-oriented $(n=25$, $3 \%$ ), and lead by example behaviours ( $n=26,3 \%)$. In demanding situations, more task-oriented behaviours were reported. In study two, staff nurses' ratings of their SCNs' behaviours, (Monitoring and Recognising) were related to staff compliance with rules and patient injuries 
(medium severity), while the self ratings of SCNs indicated that Supporting behaviours were linked to lower infection rates and Envisioning change behaviours were linked to lower infection and other safety indicators for both patients and staff.

Conclusion: This study provides preliminary data on the usability of a standard leadership taxonomy (Yukl et al 2002), and the related MPS questionnaire, on a nursing sample. The findings indicate the relevance of several leadership behaviours of SCNs for ensuring a safer ward environment and contribute to the evidence base for their leadership skills training.

Key words: interview, leadership, Managerial Practices Survey, nursing, patient safety, senior charge nurses 


\section{What is already known about the topic?}

- The role of nurse leaders in achieving desired organizational changes has been demonstrated.

- Less empirical evidence exists on leadership behaviours that support nurses in their work to improve safety for patient and staff at the ward level.

- Most research to date has focussed on the task and relations-oriented behaviours of nurses in relation to ward performance. Less is known about nurse leader behaviours in relation to safety.

\section{What this paper adds}

- This study investigated senior charge nurses' leadership behaviours (including changeoriented) in relation to patient and staff safety outcomes.

- The interview study demonstrated that relations and task-oriented behaviours are reported the most frequently by the senior charges nurses. During more demanding situations, the focus of the leader was on the task, compared to building relationships with the staff or developing innovative practices.

- The questionnaire survey findings indicate that monitoring and recognising behaviours of the senior charge nurses (as rated by their subordinates) are positively related to safety compliance of staff and fewer patient injuries.

- The senior charge nurses' own leadership ratings of envisioning change behaviours are associated with lower infection rates. 


\section{Introduction}

The Public Inquiry into patient safety and quality of care at the Stafford hospital in England (which had 400-1200 “excess deaths” from 2004-2008) focussed on leadership at all levels of the organisation (Francis, 2013). In high risk industries such as aviation, the crucial role of leadership for worker safety has long been recognized (Flin and Yule, 2004). The behaviours of front-line leaders have been shown to relate to staff injuries (Barling et al., 2002), organizational commitment to safety (Mullen and Kelloway, 2009; Zohar, 2002), and workers' safety behaviours (Mullen et al., 2011; Zohar and Luria, 2004). Much less is known of the leadership behaviours of nurses in relation to staff or patient safety. This paper presents two studies on leadership behaviours of senior charge nurses (SCN) who are responsible for both staff and patient safety in their hospital wards.

\section{Background}

In Scotland, a framework identifying key areas of responsibility for the SCN role includes: ensuring safe and effective clinical practice, enhancing patients' experience of care, contributing to the delivery of organizational objectives, and managing and developing team performance. Providing direct clinical care and administrative duties are central to their role functions (Scottish Government, 2008). While leadership practices are known to influence nurses' motivation and performance (Germain and Cummings, 2010; Thomas, 2012), only a few studies have identified the leadership behaviours of hospital ward leaders and even fewer measured patient safety outcomes (Wong and Cummings, 2007). SCNs' key role in ensuring patient safety (Kennedy, 2008) has been demonstrated where nurses were found to be "responsible for $86 \%$ of all interceptions" of medication errors in two US hospitals, (Leape et al., 1995, p.37). For the current study, we define safety as "the avoidance, prevention and 
amelioration of adverse outcomes or injuries stemming from the process of healthcare" [(patients) or from working in healthcare (nursing staff)] (adapted from Vincent, 2006, p.14). In order to achieve the desired organizational change to achieve this, an examination of the role of the first line nursing leaders that distribute and allocate resources to ensure the quality of patient care is necessary (Agnew et al, 2012; Ellefsen, 1998). Given the senior charge nurses' crucial role as ward leaders, the focus of this research is on nursing leadership at the hospital ward level.

There are two approaches to measuring leaders' influence on industrial safety; general considering all leadership activities (Zohar, 2000) versus safety specific - only examining those directed specifically at safety issues (Barling et al., 2002; Mullen et al., 2011). For this investigation, we examined the general leadership behaviours of ward leaders and how they

relate to safety. The goals of the studies reported here were: a) to identify the day to day leadership behaviours of senior charge nurses/ward sisters at the hospital ward level and to test if these fitted a standard leadership model (study one), and b) to determine the impact of these leader behaviours on safety-related outcomes, both for patients and ward staff (study two).

\section{The hierarchical leadership taxonomy}

Dominant frameworks for investigating worksite leadership behaviours have focused on two main categories: namely, task versus relations-oriented behaviours in the situational models (Amabile et al, 2004; Yukl, 2008), also referred to as 'initiating structure' and 'consideration' in early leadership research (Judge et al, 2004). Another popular approach is the transformational and transactional model of leadership styles, applied in industrial (Avolio et al., 1999) and nursing research (Germain and Cummings, 2010), see Wang et al (2011) for a recent meta-analysis. However, it has been argued that the transformational theory excludes a 
number of behaviours that are components of effective leadership, thus undermining its predictive validity (Yukl, 1999a).

In order to provide a more comprehensive framework, Yukl (1999b) developed the Hierarchical Leadership Taxonomy measured by his Managerial Practices Survey (MPS), questionnaire. This captures three main (meta) categories of leader behaviours (task, relations, and change oriented) and the relevance of each of these behaviours for different outcomes has been demonstrated (Yukl et al., 2002). According to the model, the primary objective of the task behaviours is improving productivity by appropriate allocation of resources and personnel, and ensuring the reliability of the operations to accomplish a task. Task behaviours include, short term planning, clarifying roles, and monitoring operations. The main objectives of the relations oriented behaviours are; developing cooperation and trust within the team members, as well as increasing their commitment with the organization. Relations behaviours include consulting, supporting, recognising, developing and empowering. Previous research has shown the positive effect of these leadership behaviours for workers' job satisfaction and lower turnover (Yukl, 2006). Supporting behaviours of the leaders are a core component of consideration behaviours (Yukl et al., 2002) and have been linked to follower satisfaction, motivation and leader effectiveness (Judge et al., 2004). The change oriented behaviours relate to implementation of change (i.e. initiatives) within the organization: External monitoring, encouraging innovative thinking, taking risks for change and envisioning change constitute the change behaviours. These behaviours indicate the leaders' commitment to change and have been found to be positively related to managerial effectiveness, individual and team performance (see Michel et al., 2011; Yukl, 2008). 
For the current study, we adopted Yukl et al's (2002) Hierarchical Leadership Taxonomy, as the framework for understanding the leadership behaviours of senior charge nurses for three main reasons. First, as stated above, the framework covers a range of leader behaviours relevant to first line nurse managers. Several nursing studies (using different measures) have shown both the direct and indirect influence of task and relations oriented behaviours of nurse leaders and managers on outcome measures, such as staff satisfaction, staff relationships, staff well being, work environment, and productivity (Cummings et al., 2010). Relations-oriented behaviours of nurse leaders have been linked to higher staff satisfaction (Havig et al., 2010; Sellgren et al., 2008), productivity, and organizational commitment perceptions of staff nurses (Chiok Foong Loke, 2001). Task-oriented behaviours of nurse leaders were found to be negatively related to conflict management (Hendel et al., 2005), staff well-being (Storduer et al., 2005), and staff satisfaction (Chen et al., 2005). It has been also been shown that during the implementation of organizational change in the NHS, the effectiveness of clinical managers' leadership competencies were related to different activities to achieve change. Relationsoriented leaders were more likely to communicate the need for change, while task-oriented leaders directed their attention to mobilizing the staff and evaluating the implementation of change processes (Battilana et al., 2010).

Second, compared to the transformational model of leadership, the Yukl framework treats relations and change oriented behaviours as separate categories. This is important for determining the specific influence of particular leadership behaviours on different outcome measures (e.g. task performance, safety, job satisfaction). Moreover, in a previous metaanalysis (Judge et al., 2004), the strong associations between initiating structure and leader job performance and group-organization performance were demonstrated. Yukl et al (2002) describe the clarifying role as a core component of initiating structure (task focused leadership), 
but positive forms of these behaviours are not included in the transactional leadership model (Michel et al., 2011). Third, as change-oriented behaviours rely on identifying the need for change, communicating this, and the necessary innovation (Yukl et al., 2002), we believe that these behaviours might be especially relevant for the NHS which is continually subjected to organizational change (Frederick et al., 2011).

The nursing literature on leadership effectiveness has tended to focus to patient-related outcomes, such as satisfaction or mortality (Wong et al., 2007); only a few studies have examined the leader behaviours from a patient safety perspective. Relational leadership (acting as a role model) was indirectly associated with reductions in patient falls and medication errors, (Houser, 2003) and was also linked to a decreased number of patient fractures and complications of immobility (Anderson et al., 2003). However, the level of nurse manager support for staff was not related to the frequency of patient adverse events across 21 surgical and medical wards in US hospitals (Boyle, 2004).

In summary, while relations focused behaviours of nursing leaders have been positively related to staff outcomes, such as staff satisfaction, health, well being, and organizational commitment, more inconsistent findings have been reported for task oriented leadership behaviours. Despite the growing evidence linking change-oriented leadership behaviours with organizational outcomes, such as team climate and team performance, limited attention has been given to such behaviours in the nursing literature. There is only a limited literature linking ward nurses' leadership behaviours to either patient or staff safety.

Effective leadership requires changing behaviour in accordance with situational demands (Yukl and Mahsud, 2010), e.g. a crisis, balancing competing values, dealing with subordinates 
with different skills (Yukl et al., 2010) and desired goals (Michel et al., 2011). Shifts in leadership behaviours as a function of task load, task complexity, and the novelty of the situation have been linked to team performance and effectiveness (Klein et al., 2006, Kunzle et al., 2010). With this literature in mind, we set out to identify the specific types of nurse leader behaviours that are typically used in ward setting, in both routine and demanding situations, before attempting to establish their relative impact on specific outcomes, such as safety. By focussing on the relevance of these behaviours to both worker and patient safety outcomes in hospital wards, we hope to contribute to the emerging literature by providing data on how the behaviours of front line leaders at the hospital ward level relate to a safer ward environment.

\section{Overall Objectives and Hypotheses}

The proposed study set out to identify specific leadership behaviours of senior charge nurses at the hospital ward level and to determine the relevance of these behaviours to the SCNs' wards' worker and patient related safety outcomes (e.g. worker safety behaviours, patient infection rates). To address this purpose, the study was designed in two distinct, but interrelated phases. First, semi-structured interviews were conducted with senior charge nurses; second, self-leadership ratings of SCNs and upward ratings from their staff nurses were used and compared to safety outcome measures.

The research hypotheses were as follows:

H1: Senior charge nurses will report engaging in more task and relations-oriented leadership behaviours compared to change-oriented behaviours.

H2: Relations and change focus leadership behaviours of senior charge nurses will be more strongly and positively related to desirable safety behaviours of staff nurses, compared to taskoriented leadership behaviours. 
H3: Relations and change focus behaviours of senior charge nurses will be more strongly and negatively related to adverse patient safety and worker safety outcomes, compared to taskoriented leadership behaviours.

\section{Study One: Interviews with Senior Charge Nurses}

The main aim was to elicit the typical leadership behaviours used by SCNs during their day to day activities without any specific focus on safety and the second aim was to test the relevance of Yukl's Hierarchical Leadership Taxonomy in this context.

\section{Methods}

Interview Design

Semi-structured, one-to-one interviews (Fontana and Frey, 1998) were conducted to obtain data on senior charge nurses' (SCN) perceptions of their role as a hospital ward leader and their associated leadership behaviours. This approach meant that interviewees could discuss topics in detail enabling flexibility and control (Denscombe, 2007).

The interview schedule was developed from the clinical leadership (e.g. Reader et al., 2011) and nursing literatures (e.g. RCN, 2009), as well as Yukl et al's (2002) leadership framework. Participants were first asked to describe their typical work day in order to gain familiarity with their normal activities in their role as a senior charge nurse. They were then asked about effective and ineffective leadership behaviours for the SCN (questions (Q 2-3). These questions were intended to reveal which leadership behaviours the SCNs regarded as specifically important for their role as a hospital ward manager. In order to determine whether their leadership behaviours altered depending on the context, we asked the participants to describe 
their leadership behaviours both in routine and demanding situations (Q 4-5). They were asked which performance targets they had to meet within their role as a SCN (Q6), and how these performance targets were influenced through their leadership behaviours (Q7). Next, if the interviewee did not state any safety-related outcomes in the previous question, they were asked whether their leadership behaviours had an impact on both patient and worker safety outcomes and the ways they influenced these outcomes. Finally, the participants were asked whether they had received any formal leadership training.

\section{Participants}

One large acute NHS hospital in Scotland agreed to take part in the study. The target group $(\mathrm{N}=25 \mathrm{SCN})$ was determined based on advice obtained from the hospital management team to utilize only medical and surgical wards (typically 40 beds), managed by a single senior charge nurse. Given practical constraints, such as staff shortages, the sample size was also influenced by the recommendation that a set of 12 interviews was sufficient for the development of meaningful themes (Guest et al., 2006).

The SCN were informed of the study by the first author attending a nurse managers' meeting. The 15 SCNs who volunteered to take part (response rate 60\%) were all female and their work experience as a nurse ranged from 11 to 38 years, and as a SCN from 1 to 3 years. They had worked in their current ward from 1-5 years and were responsible for 9 - 60 ward staff. The majority $(n=12)$ reported receiving leadership training, of whom, eight had attended both mandatory and voluntary training and four had had voluntary training.

\section{Procedure}


The SCNs who agreed to participate were contacted via email to arrange the interview time and location. The 15 interviews were conducted by the first author and digitally recorded to allow transcription. Interviews lasted $26-60$ minutes $(\mathrm{Mean}=40 \mathrm{~min}, \mathrm{SD}=9.9)$.

\section{Data Analysis}

The interviews were transcribed verbatim and were subjected to qualitative content analysis, with words and groups of words as the unit of analysis. A deductive approach (Elo and Kyngas, 2007) was used based on an a priori coding system; the Hierarchical Leadership Taxonomy (Yukl et al., 2002). The coding strategy, with example behaviours extracted from the interview data, is described in the results section (Table 1). The transcripts were coded by two psychologists to determine the inter-rater reliability of extracted constructs.

In the first step, two interview transcripts extracted at random were coded by both coders based on the instruction materials developed by the first author; including the explanation of the taxonomy and the definitions of 12 behaviours under three categories. Their results were then compared and discussed and it was decided to include an additional category from an earlier version of MPS (Yukl and Van Fleet, 1982); "lead by example" as it was not possible to code all the data within the existing framework. The remaining transcripts were coded by both coders. Krippendorff's alpha was tested using IBM SPSS 19 (SPSS Inc., Chicago, IL, USA) to establish the inter-rater reliability as it can be used with any number of raters, with missing or incomplete data, independent of the sample size (Hayes and Krippendorff, 2007). Although there is no universally accepted standard cut-off score, values over $\geq .80$ have been suggested as satisfactory levels of agreement among the raters (Krippendorff, 2004). The frequency of each leadership behaviour was then calculated both at the meta-category and the behaviour level. 


\section{Ethical consideration}

Ethical approval was obtained from the NHS National Research Ethics Service (NRES): 11/AL/0092, as well as from the University.

\section{Results}

Inter-rater reliability: The results showed that all the constructs had satisfactory inter-rater reliability; overall $\alpha=0.87$, and for each category; task-oriented behaviours, $\alpha=0.82$, relationsoriented behaviours, $\alpha=0.92$, and change oriented behaviours, $\alpha=0.85$.

\section{SCNs' leadership behaviours}

A total of 763 individual behaviours from the $15 \mathrm{SCN}$ interviews were analysed. The table below (Table 1) demonstrates the coding strategy and the example behaviours extracted from the data.

Table 1 Coding strategy: Hierarchical taxonomy of leadership behaviours with examples of nurses' statements (Yukl et al., 2002)

\begin{tabular}{|c|c|c|}
\hline Meta categories & Behaviours & $\begin{array}{l}\text { Example behaviours extracted from } \\
\text { interview data }\end{array}$ \\
\hline \multirow[t]{3}{*}{ 1. Task-oriented } & Clarifying roles & $\begin{array}{l}\text { Some people aren't so compliant as others } \\
\text { and they have to be told all the time but if } \\
\text { that goes on, if they're doing it all the time } \\
\text { then I'll set them a standard. }\end{array}$ \\
\hline & Monitoring-operations & $\begin{array}{l}\text { We also have to audit the number of drug } \\
\text { errors every month. }\end{array}$ \\
\hline & Short-term planning & $\begin{array}{l}\text { If we have more than eleven patients then } \\
\text { we have to have nurses in on overtime. }\end{array}$ \\
\hline \multirow[t]{2}{*}{ 2. Relations-oriented } & Consulting & $\begin{array}{l}\text { The best way, ask them what they think, } \\
\text { whether they have suggestions as to the } \\
\text { best way of doing but at the end of it all, it } \\
\text { would be my decision how we do it and } \\
\text { hopefully with their participation. }\end{array}$ \\
\hline & Supporting & $\begin{array}{l}\text { I would try and speak to them on their own } \\
\text { to find out why there was a problem or } \\
\text { what the conflict was. }\end{array}$ \\
\hline
\end{tabular}




\begin{tabular}{|c|c|c|}
\hline & Recognising & $\begin{array}{l}\text { If they work hard and get their work done, } \\
\text { then they're rewarded. }\end{array}$ \\
\hline & Developing & $\begin{array}{l}\text { Need to develop their leadership skills, } \\
\text { you put them on a course or put them to } \\
\text { shadow one of the ones who are in charge. } \\
\text { It's when you deal with things that you } \\
\text { shouldn't necessarily have to deal with, } \\
\text { you can delegate that work to somebody } \\
\text { else. }\end{array}$ \\
\hline \multirow[t]{5}{*}{ 3. Change-oriented } & Envisioning change & $\begin{array}{l}\text { I've come in and embraced what they're } \\
\text { doing and thought "Right, let's do more, } \\
\text { let's show the whole Board what we do, } \\
\text { what we can do". }\end{array}$ \\
\hline & Taking risks for change & $\begin{array}{l}\text { It's difficult for junior staff to approach a } \\
\text { consultant but for me I don't mind. }\end{array}$ \\
\hline & $\begin{array}{l}\text { Encouraging innovative } \\
\text { thinking }\end{array}$ & $\begin{array}{l}\text { That's one of my sayings "If we always do } \\
\text { what we've always done, we'll always } \\
\text { have what we've got now". }\end{array}$ \\
\hline & External monitoring* & - \\
\hline & Lead by example & $\begin{array}{l}\text {... to be a role model for timekeeping and } \\
\text { being good with communication with } \\
\text { patients and stuff. }\end{array}$ \\
\hline
\end{tabular}

* No "external monitoring" behaviours were reported by the interviewees

Relations-oriented behaviours were found to be the most frequently reported by the SCN in relation to their daily role as a ward leader, followed by task-oriented, with fewer changeoriented, and lead by example behaviours. Although task and relations oriented behaviours were mentioned by all $15 \mathrm{SCNs}$, eight SCNs (53\%) reported change-oriented and $10 \mathrm{SCNs}$ (67\%) reported engaging in leading by example behaviours. 
Table 2 Frequencies and percentages of leadership behaviours reported by the SCNS

\begin{tabular}{llcc}
\hline Meta categories & Behaviours & Frequencies & Percentages \\
\hline Task-oriented & Clarifying roles & 104 & $30 \%$ \\
& Monitoring-operations & 153 & $45 \%$ \\
Total & Short-term planning & 85 & $25 \%$ \\
\hline Relations-oriented & Consulting & $\mathbf{3 4 2}$ & $\mathbf{4 5 \%}$ \\
& Supporting & 33 & $9 \%$ \\
& Recognizing & 183 & $50 \%$ \\
& Developing & 26 & $7 \%$ \\
\multirow{2}{*}{ Total } & Empowering & 76 & $21 \%$ \\
\hline Change-oriented & Envisioning change & 52 & $14 \%$ \\
& Taking risks for change & $\mathbf{3 7 0}$ & $\mathbf{4 9 \%}$ \\
\hline \multirow{2}{*}{ Total } & Innovative thinking & 22 & $88 \%$ \\
Lead by example & External monitoring* & 2 & $4 \%$ \\
\hline Overall Total & & - & - \\
& & $\mathbf{2 5}$ & $\mathbf{3 \%}$ \\
\hline
\end{tabular}

* No "external monitoring" behaviours were reported by the interviewees

\section{Leadership during demanding situations}

Senior Charge Nurses described a number of factors that might contribute to a demanding situation within the ward. The most frequently mentioned was related to staff shortages, where $87 \%$ of the interviewees reported that one demanding situation was not having an adequate number of staff to handle the workload. They described their leadership role as a SCN on a demanding day by stating;

"I suppose you communicate slightly differently to them, you're speaking to them. It's more task orientated. You're telling them what you're expecting them to do that day."

"If I'm short staffed or if I'm stressed, I can't support my staff. How I should be supporting them because I'm working as a nurse, I'm not working as a senior charge nurse."

"The reality is that I knew my staff were feeling pressure so I've actually taken away from their workload which is putting it a lot more on me because I can't delegate work to them at the moment. I know they're feeling pressured which is putting a lot of pressure on me because I have to do all the work so I've not been able to delegate anything to them." 
SCNs also mentioned patient flow, bed pressure, staff conflicts, high patient dependency, and administrative tasks that might cause demand and have an effect on their daily leadership roles:

"I have to always make sure I'm adequately staffed to cope with the extra day patients that turn up. There's junior staff on the ward, I will also go out to help them so that they don't get too stressed and advise them as well."

"I would say a demanding situation is when staff are not getting on. If it is related to staff conflicts, it's about gathering the facts and not rushing in."

"I wouldn't be in the office in a demanding situation. The clinical area always takes priority, administration will have to wait. I'm quite concerned that with all the increasing administration piled onto the ward sisters, plus they're expecting us to be in the clinical area eighty per cent of the time, it's impossible"

This type of increased demand required them to adapt their SCN role, such as working more clinically, as opposed to leading the team. Research in other healthcare teams has demonstrated the requirement of more directive leader behaviours and the dynamic delegation of the responsibilities among the team members in high workload and complex cases (Klein et al., 2006; Yun et al., 2005). Despite the fact that relations focused behaviours were reported most frequently by the SCNs, when asked about their leadership styles during the demanding situations, they said they communicated differently with their team members and engaged in less delegating behaviours. They focussed on accomplishing the clinical responsibilities and achieving the tasks, rather than supporting their team members during a difficult situation, which in turn led to an increase in their tasks.

In high workload situations, SCNs tried to balance appropriate levels of task and relations oriented leader behaviours to meet the competing objectives, when clinical responsibilities become a priority compared to administrative duties. In this case, the SCN takes on a more 'hands on' clinical role rather than delegating to the staff nurses, even though their skills were adequate to handle the situation. Another behaviour the SCNs reported was directing 
individuals to perform specific tasks rather than consulting the staff nurses on the decisions being made (Clarifying roles versus Consulting).

\section{Leadership and performance targets}

All the performance targets mentioned by the SCNs were related to patient safety. For example, Hand hygiene, Clinical Quality Indicators such as food, fluid, nutrition, slips trips \& falls, and HEAT - Health Improvement, Efficiency, Access to Services and Treatment- targets (e.g. infection control) were stated as major performance targets that SCNs need to meet within their wards. In addition to safety targets, $20 \%$ of the interviewees reported ward budget as one of their performance targets and staff appraisals were also mentioned. They also acknowledged the impact of their leadership behaviours on achieving the desired outcomes especially by recognising staff behaviours and envisioning change.

"It is just reinforcing staff about how it does improve and have an impact on patient care if are doing these things. Giving some praise and recognition... It's sort of giving recognition for staff, acknowledging good behaviour to other team members as well and then I highlighted it to my manager. I think it is definitely giving praise and recognition for a job well done is important."

"My leadership is to be positive. For example, around hand hygiene, around fluid, food nutrition, the importance of it and highlighting the reason why we're doing it. Again, it's about explaining to staff the reason, the rationale. Why are we doing this? And then it's amazing, once you start displaying scores on the door as we say, your staff become very proud that they're doing well and they want to do well and they'll ensure then it has a knock on effect."

In order to achieve the targets set by the organization and increase the team performance, SCNs reported the effectiveness of certain leader behaviours such as; acknowledging the good behaviour of staff nurses, describing the reasons behind the desired outcomes and expressing the rationale for the targets to the team members. 


\section{Conclusion of study one}

Yukl's leadership taxonomy with three meta-categories and 12 specific behaviours was found to be a reliable method of coding the SCN interviews. A higher frequency of task and relations oriented leadership behaviours were reported, compared to change-oriented. As the focus was to determine the patterns of behaviours SCNs use in their daily leader role and to test the relevance of a standard leadership taxonomy in the hospital ward context, simple frequencies of behaviours were reported but no comparisons were made. For demanding situations, the majority of SCNs indicated a change in their leadership styles and reported task focused behaviours to be more effective. This fits with the literature suggesting the importance of task oriented behaviours to improve productivity as the focus of the leader shifts from the needs of team members to the accomplishment of the task (Yukl, 2008). In order to meet patient and worker safety targets, relations and change behaviours were reported by the SCNs. This suggests that the SCNs require different leadership behaviours for particular situations they have to manage in their wards.

Although participants were from different types of wards, these findings should be interpreted cautiously, given the small sample from one hospital. It was not possible to conclude which leadership behaviours were more effective in predicting safety-related outcomes without linking these perceptions with performance data. Therefore, in study two we attempted to identify which of the leadership behaviours of SCNs were predictive of both patient and staff safety outcomes.

\section{Study 2: Questionnaire Study: Leadership behaviours and safety}

A qualitative analysis in study one identified the set of leadership behaviours senior charge nurses use in their daily roles. Then the relevance of Yukl's leadership taxonomy was 
determined in relation to these behaviours within the hospital ward context. There were differences reported for leadership behaviours during demanding situations. Although the interview study systematically identified the frequency of SCNs' leadership behaviours, we cannot infer their effectiveness on ensuring both safer patient care and staff safety. Therefore to achieve this aim, in order to identify to what extent these patterns of SCNs' leadership were associated with safety-related outcomes, a cross-sectional questionnaire survey was conducted between December 2011 and January 2012 with the same SCNs, using the Managerial Practices Survey (Yukl et al., 2009) as the leadership measure. Safety behaviours and safety related performance metrics used as the outcome variables.

\section{Procedure}

This study was classed by NRES as a Service Evaluation and did not require additional approval. Ethical approval was obtained from the University Ethics Committee.

The first author attended a senior charge nurse meeting and also contacted the participants of the first study via email. Overall, 19 SCNs replied, 15 agreed to participate, and 4 declined. Ward nurses were asked to anonymously rate their ward leaders (SCNs) using the MPS questionnaire (Yukl et al., 2002) of leadership behaviours. The SCNs were asked to complete the self-rating version. Each SCN was sent a questionnaire packet including an introduction letter from the researcher, a copy of the SCN Managerial Practices Survey: Self Report, seven Upward Managerial Practices Surveys to be given to nurses who directly reported to them (upward appraisal) with a covering letter. Sealable envelopes were provided for completed questionnaires addressed to the researcher's university address, or alternatively, directly to the box provided in their department. Completion and return of a questionnaire was taken as an indication of consent to participate. In order to encourage participation, each SCN was offered 
a confidential individual feedback report showing how her own scores compared to the aggregated upward rating scores from her ward nurses.

\section{Participants}

Participants were nurses (all female) from 15 medical and surgical wards at the same Scottish NHS acute hospital as study one. A total of 82 staff nurses (SN) rated 15 SCNs to whom they directly reported (including $10 \mathrm{SCNs}$ from study one). Most of the staff nurses (SN) had worked in their current ward 1-5 years, 23\% (6-10 years), 13\% (11-15 years). Most (85\%) SNs had worked with their current SCN for more than a year.

\section{Measures}

Leadership behaviours were measured by 48 items from the short version of Yukl's MPS (Yukl et al., 2002; Yukl et al., 2009) assessing task-oriented, relations-oriented, and change oriented leadership, with 16 specific behaviours (subscales) for each category. For relations oriented behaviours; Encouraging cooperation (communicating the importance of teamwork among team members) was included as a subscale. Explaining need for change and Facilitating collective learning, measured change oriented behaviours. This version of the MPS had two leader behaviours (Problem solving and Lead by example) that were not part of the original taxonomy. Each of the 16 subscales consisted of three items with a 5-point Likert scale (ranging from "not at all" (1) to "to a very great extent" (5) with a "Don't Know or Not Applicable" option) measuring the perceptions of frequency which the behaviour is used by the leader (the $\mathrm{SCN})$. As noted above, the MPS was chosen as it is one of the most comprehensive leadership measurement tools, and explains more variance in the prediction of managerial effectiveness compared to other leadership instruments (Michel et al., 2011). The reliability and the validity 
of the tool were established previously (Michel et al., 2011; Yukl et al., 2002), the internal consistency values of the scales ranged from .75 to .93 (Yukl et al., 2009).

Safety behaviours such as participating in safety activities or complying with rules were shown to be key worker safety outcome variables in both industrial (Clarke, 2006; Neal et al., 2000; Neal and Griffin, 2006) and healthcare safety research (Zohar et al., 2007). Self-reports of these behaviours have been associated with a reduction in future accident rates (Neal \& Griffin, 2006). In Scottish NHS acute hospitals, clinical staff perceptions of supervisors' and management's commitment to safety and of adequate staffing levels were positively related to safety compliance behaviours. But when staffing levels were perceived less favourably, a decrease in safety participation was reported (Agnew et al., 2013), indicating the possible mitigating effect of a good teamwork climate on inadequate staffing (Siassakos et al., 2011).

As a measure of safety outcome for staff, we included the ten item scale used by Agnew et al. (2013), to measure self reports of staff nurses' safety compliance and participation behaviours (rated on a five-point scale ranging from "strongly disagree" to "strongly agree"). Safety participation was assessed by 4 items (Neal et al., 2000); an example item for this scale is; "I put in extra effort to improve the safety of the workplace". For safety compliance, 6 items were incorporated from industrial research (Mearns et al., 2003) and reworded for nurses; e.g. "I get the job done better by ignoring some rules". (Rules for nurses include behaviours such as hand washing and reporting incidents). These scales have been used in safety research and showed satisfactory reliability (Agnew et al., 2013; Cullen and Hammer, 2007; Turner et al., 2012).

\section{Safety performance data:}


For each SCN, the following data were collected from the hospital management for their ward as patient or staff safety outcome measures.

Infection rates for patients were measured using the number of Clostridium difficile infection (CDI) and Staph Aureus Bacteraemias (SAB) cases in each unit that were documented by the hospital incident reporting system for six consecutive months (September 2011 - February 2012). CDI is an important healthcare associated infection and a health threat in Scotland (Health Protection Scotland, 2012). Patients with this infection were counted once even if they had multiple positive tests. However, patients with a CDI toxin positive stool sample after a 28-day gap with no positive toxin tests were counted as a new episode. SAB is another healthcare associated infection and defined as "a gram positive bacterium which colonises the nasal cavity of about $30 \%$ of the healthy population. Although this colonisation is usually harmless, S. aureus may cause serious infections." (Cairns et al., 2010, p.111). SAB infections are generally associated with healthcare interventions, as a result of failures to implement infection prevention methods. For the SAB data, patients were counted once even if they had multiple positive tests within 14 days.

Patient injuries were assessed using the total number of incidents that resulted in injury, harm or ill-health to the patient, as well as the total number of near misses with no injury or harm occurrence. The data were collected for each unit from the hospital incident reporting system (between December 2011 and February 2012). Incident severity levels were obtained from the hospital incident reporting system recorded for patient injuries. Low severity incidents were defined as patient injuries resulted in zero or minor injury and Medium level severity refers to moderate injuries. 
Staff incidents were calculated by the total number of abusive, violent, disruptive or selfharming behaviour of patients towards the staff, plus accidents including slips, trips, falls, exposure to blood and body fluids, needlesticks or other hazards. The data were obtained for each unit from the hospital incident reporting system (September 2011 - February 2012).

\section{Analysis Strategy}

Data from the leadership rating forms were analyzed using IBM SPSS Statistics Version 19. Leadership behaviours were treated as a group-level construct since the focus of the study was on behaviours that SCNs directed towards to the group of staff nurses in their ward as a whole. For this reason, we aggregated each set of upward leadership scores for a given SCN to the ward level. Then, Cronbach's (1951) alpha was used to measure internal consistency for the dimensions (i.e. leadership scales and safety behaviours scales) with sufficient aggregation indices. In order to determine the extent to which the leadership behaviours related to the safety behaviours and safety performance data, correlational analyses were conducted using nonparametric tests (criterion validity).

\section{Results}

Aggregation analyses

Both theoretical and statistical support is required for aggregating the variables (Bliese, 2000). In order to achieve this, prior to aggregating the leadership and safety behaviours to ward level, we assessed within-group homogeneity and between groups variation in order to justify the aggregation procedure by calculating a number of aggregation indices (i.e., rwg, ICC(1), ICC(2), ) for each of the leadership dimensions and self-reported safety behaviours scales. Firstly, to assess within-group inter-rater agreement, $r w g(\mathrm{j})$ statistic (LeBreton and Senter, 2008) was computed. As a common rule-of-thumb, $r w g(j)$ values $\geq .70$ are generally 
considered necessary to justify aggregation (Tabachnick and Fidell, 2003). ICC(1) and ICC(2) provides additional evidence for within group agreement. While ICC(1) relates to proportion of variance in a given variable that can be explained by the group membership whereas $\operatorname{ICC}(2)$ refers to the reliability of the group means (Bliese, 2000). Although there is no universally accepted cut-off values for ICC scores, it has been reported that a criterion value of .12 or above for ICC(1) and for ICC(2) criterion values between .60 and .70 have been used for aggregation (Costa and Anderson, 2011). As can be seen from Table 3, the aggregation indices for Monitoring, Supporting, Lead by example, and Envisioning change suggested adequate levels of agreement. Although Recognising, Delegating, and Safety compliance scale $r w g(j)$ values were slightly lower than the cut-off value, we decided to analyze the data on these three scales at the group level because 1) other indices provided support for the aggregation, 2) literature (LeBreton and Senter, 2008) warns against decisions based on rigid $r$ wg(j) cut-off values where moderate levels of agreement has been suggested as sufficient to establish necessary conditions for agreement. The rest of the scales were excluded from the further analyses since the aggregation indices did not support the aggregation of these constructs to the ward level.

Table 3 Values for aggregation indices on upward MPS scores

\begin{tabular}{lccc}
\hline MPS categories & $\boldsymbol{r w g}(\mathbf{j})$ & ICC1 & ICC2 \\
\hline Monitoring (Task Oriented) & .84 & .48 & .92 \\
Supporting (Relations oriented) & .87 & .81 & .85 \\
Delegating (Relations oriented) & .68 & .82 & .87 \\
Recognizing (Relations oriented) & .68 & .76 & .80 \\
Lead by Example (Relations oriented) & .92 & .95 & .95 \\
Envisioning Change (Change oriented) & .79 & .67 & .76 \\
Safety Compliance (Safety behaviour) & .68 & .64 & .80 \\
\hline
\end{tabular}

Descriptive analyses 
We compared the mean scores of the 6 behaviour scales for SCNs' self-ratings and the composite subordinate ratings using independent t-tests (Table 4). The results showed that none of the leadership scores obtained from the staff nurses were significantly different from selfreports of SCNs' leadership behaviours except Monitoring. The Monitoring mean score obtained from the subordinates was significantly higher than the SCNs' self-ratings. Therefore, non-existing systematic differences showed that self-ratings of the SCNs were not inflated compared to subordinate ratings. In order to preserve confidentiality, the descriptive data on hospital safety performance are not reported.

Table 4 Descriptive results for the subordinates' and self-report ratings of leadership behaviours

\begin{tabular}{lccccc}
\hline Leadership behaviours & \multicolumn{2}{c}{ Subordinates } & \multicolumn{3}{c}{ Self } \\
\hline & Mean & $S D$ & Mean & $S D$ & $t$ \\
\cline { 2 - 6 } Monitoring & 4.19 & .80 & 3.71 & .41 & $3.46^{*}$ \\
Supporting & 4.15 & .78 & 4.22 & .50 & .33 \\
Recognising & 3.89 & 1.02 & 4.13 & .90 & .85 \\
Delegating & 3.87 & .97 & 3.80 & .57 & .30 \\
Lead by example & 4.33 & .86 & 4.44 & .66 & .51 \\
Envisioning change & 3.94 & .96 & 3.82 & .50 & .68 \\
${ }^{*} \mathrm{p}<.05$ & & & & &
\end{tabular}

\section{Relationships between leadership behaviours and safety-related outcomes}

In order to examine the associations between the aggregated leadership scores and the safetyrelated outcomes, correlational analyses were conducted. Because of the nature of the nonnormally distributed data, non-parametric tests were used to test the relationships, and Spearman Rho correlation coefficients were calculated (see Table 5). The only significant correlations with respect to safety performance data were Monitoring and Recognising behaviours of SCNs as rated by the staff nurses. The results showed a positive correlation between Monitoring behaviours of SCNs and Safety compliance behaviours of their staff 
Table 5 Correlations between subordinates' leadership ratings and safety-related outcome measures (Based on the aggregated data)

\begin{tabular}{|c|c|c|c|c|c|c|c|c|c|c|c|c|c|c|}
\hline Variable & Alpha & 1 & 2 & 3 & 4 & 5 & 6 & 7 & 8 & 9 & 10 & 11 & 12 & 13 \\
\hline \multicolumn{15}{|l|}{ MPS } \\
\hline 1. Monitoring & .88 & & & & & & & & & & & & & \\
\hline 2. Supporting & .84 & .44 & & & & & & & & & & & & \\
\hline 3. Delegating & .94 & .38 & $.66^{* *}$ & & & & & & & & & & & \\
\hline 4. Recognizing & .94 & $.59^{*}$ & $.89 * *$ & $.66^{* *}$ & & & & & & & & & & \\
\hline 5. Lead by Example & .94 & $.84 * *$ & $.55^{*}$ & $.55^{*}$ & $.59^{*}$ & & & & & & & & & \\
\hline 6. Envisioning Change & .92 & .28 & $.72 *$ & $.66^{* *}$ & $.71 * *$ & .49 & & & & & & & & \\
\hline \multicolumn{15}{|l|}{ Safety outcomes } \\
\hline 7. Safety Compliance & .80 & $.55^{*}$ & .43 & .20 & .43 & .43 & .41 & & & & & & & \\
\hline 8. $\mathrm{CDI}$ & - & .01 & -.03 & .30 & -.06 & .04 & -.07 & -.02 & & & & & & \\
\hline 9. SBA & - & -.14 & -.07 & .22 & -.20 & -.06 & -.06 & $-.60^{*}$ & .28 & & & & & \\
\hline 10. Total Infection Rates & - & .04 & .03 & .46 & -.04 & .10 & .00 & -.27 & $.83^{* *}$ & $.74 * *$ & & & & \\
\hline 11. Patient Injuries & - & -.01 & -.09 & -.07 & -.25 & .13 & -.13 & -.23 & .25 & .02 & .14 & & & \\
\hline 12. Staff Incidents & - & .05 & -.28 & -.02 & -.28 & .25 & .25 & -.09 & .32 & .12 & .24 & .43 & & \\
\hline 13. Severity - Low & - & -.03 & -.07 & -.04 & -.24 & .12 & -.04 & -.22 & .26 & .01 & .14 & $.99 * *$ & .41 & \\
\hline 14. Severity Medium & - & -.33 & -.50 & .33 & $-.59 *$ & -.21 & -.21 & -.48 & .09 & .01 & -.03 & $.65^{* *}$ & .33 & $.62 *$ \\
\hline
\end{tabular}


nurses $(\mathrm{r}=.55, \mathrm{p}<.05)$, and a negative association between Recognizing behaviours and Severity of the incidents to patients $(\mathrm{r}=-.59, \mathrm{p}<.05)$. These results suggest that when SCNs engage in more monitoring behaviours, their staff nurses report more safety compliance behaviours and when they show higher frequency of recognising behaviours, less incidents (of medium severity) are reported at the unit level for patients.

Although, leadership research argues that subordinate ratings of leadership behaviours are more valid in predicting leadership effectiveness compared to self-ratings, both sources predict leader advancement equally well (Kim and Yukl, 1995). For exploratory reasons, we also examined whether safety-related outcomes were predicted better by SCNs' own leadership ratings compared to the staff nurses' leadership perceptions of their SCNs. The results (Table 6) of the non-parametric tests (Spearman Rho) revealed that five of the correlations were significant $(\mathrm{p}<.05)$ for self-reported leadership behaviours. Self-ratings of Envisioning change behaviour were found to be negatively related to CDI $(r=-.56, p<.05)$, SBA $(r=-.61, p<.05)$, and staff incidents $(\mathrm{r}=-.56, \mathrm{p}<.05)$. Moreover, both the self-reported Supporting $(\mathrm{r}=-.52$, $\mathrm{p}<.05)$ and Envisioning change behaviours $(\mathrm{r}=-.70, \mathrm{p}<.05)$ were negatively related to total patient infection rates of the unit. Overall, these results suggest that the self-ratings of the SCNs provided useful data for predicting safety performance data at the unit level. 
Table 6 Correlations between self-reported leadership ratings and safety-related outcome measures (Based on the SCN data)

\begin{tabular}{|c|c|c|c|c|c|c|c|c|c|c|c|c|c|c|}
\hline Variable & Alpha & 1 & 2 & 3 & 4 & 5 & 6 & 7 & 8 & 9 & 10 & 11 & 12 & 13 \\
\hline \multicolumn{15}{|l|}{ MPS } \\
\hline 1. Monitoring & .74 & & & & & & & & & & & & & \\
\hline 2. Supporting & .61 & $.57 *$ & & & & & & & & & & & & \\
\hline 3. Delegating & .68 & .23 & -.06 & & & & & & & & & & & \\
\hline 4. Recognizing & .96 & $.76^{* *}$ & .51 & .26 & & & & & & & & & & \\
\hline 5. Lead by Example & .94 & .09 & .24 & $.55^{*}$ & .46 & & & & & & & & & \\
\hline 6. Envisioning Change & .83 & $.72 * *$ & $.52 *$ & -.03 & $.53 *$ & .09 & & & & & & & & \\
\hline \multicolumn{15}{|l|}{ Safety outcomes } \\
\hline 7. Safety Compliance & .64 & -.41 & -.18 & .39 & -.45 & .03 & -.16 & & & & & & & \\
\hline 8. CDI & - & -.38 & -.43 & .38 & -.34 & -.01 & $-.56^{*}$ & .39 & & & & & & \\
\hline 9. SBA & - & -.51 & -.29 & .03 & -.40 & .18 & $-.61^{*}$ & .32 & .28 & & & & & \\
\hline 10. Total Infection Rates & - & -.51 & $-.52 *$ & .31 & -.42 & .07 & $-.70 * *$ & .45 & $.83 * *$ & $.74 * *$ & & & & \\
\hline 11. Patient Injuries & - & -.10 & .32 & .24 & .21 & .34 & -.26 & .05 & .25 & .02 & .14 & & & \\
\hline 12. Staff Incidents & - & -.19 & -.02 & .15 & .08 & .09 & $-.56^{*}$ & -.10 & .32 & .12 & .24 & .43 & & \\
\hline 13. Severity - Low & - & -.10 & .31 & .22 & .20 & .32 & -.24 & .07 & .26 & .01 & .14 & $.99 * *$ & .41 & \\
\hline 14. Severity Medium & - & -.39 & .21 & -.21 & -.18 & .06 & -.31 & -.19 & .09 & .01 & -.03 & $.65^{* *}$ & .33 & $62 *$ \\
\hline
\end{tabular}




\section{Summary of study two}

The questionnaire data demonstrated which leadership behaviours of SCNs were more effective in relevance to safety outcomes. In this respect, although subordinates' descriptions of their leaders' behaviours such as Monitoring and Recognising were related to safetyoutcomes, self ratings of SCNs revealed that supporting and envisioning change behaviours were linked to safety data. Especially, envisioning change behaviours were found to more strongly predict the safety performance data compared to the rest of the leader behaviours.

\section{Discussion and directions for future research}

The goal of this study was to investigate the leadership behaviours of senior charge nurses in relation to hospital ward safety for patients and staff. The aim of the first study was to identify the set of leadership behaviours SCNs use in their daily role as a leader and to determine the relevance of Yukl's Hierarchical leadership taxonomy within a hospital ward context. We found that the three meta-categories of task, relations and change behaviours were a reliable method of coding.

We found support for the first hypothesis and demonstrated that senior charge nurses engage in task and relations-oriented behaviours more frequently compared to change-focused behaviours. Of the task behaviours, Monitoring-operations (e.g. evaluating the individual and unit performance) and of the relations behaviours, providing support to the team members were the core components of the ward leader role. 
In line with the literature demonstrating that different leadership behaviours are required in order to achieve particular performance targets (Yukl, 2008), on more demanding days with staff shortages and high patient flow, SCNs believed that it was necessary to adapt their leadership styles as they prioritize accomplishing the task compared to focusing on the emotional needs of the team members. In order to cope with pressures, they reported more task focused behaviours. More specifically, they engaged in more hands on clinical activities and displayed less consulting/ empowering behaviours. During a more stressful task, some of the SCNs reported supporting their staff by helping and advising them. However, it is important to note that, in contrast to the description of the supportive behaviour used in the Hierarchical Leadership Taxonomy, the SCNs indicated supporting their staff clinically rather than emotionally and motivationally. Additionally, although managerial duties, including administrative tasks, are a part of the $\mathrm{SCN}$ role, the increased amount of paperwork created an additional demand on the SCNs by reducing the time spent in the clinical area. The majority of the performance targets mentioned by the nurses were safety-related, perhaps because performing safely has always been a core part of the nursing role. In order to enable the staff to achieve desired organizational outcomes, SCNs reported displaying Recognition behaviours, such as "acknowledging good behaviour" and "discussing desired changes with great enthusiasm".

The interviews suggested that task and relations focused behaviours were used more frequently than change oriented behaviours, however, it was not possible in study one to determine to what extent these behaviours were effective in ensuring hospital ward safety. For this reason we conducted a second study to examine the influence of these behaviours on both staff and patient safety outcomes. In contrast to the interview data, the questionnaire data indicated higher levels of SCNs' change oriented behaviours. Staff nurses' reports of change-oriented 
behaviours of their ward leaders were not found to be related to wards' safety performance data, but the SCNs' own descriptions of Envisioning change behaviours were associated with reduced infection rates and the number of staff incidents. These findings fail to support the second hypothesis.

Only one of the task oriented behaviours (Monitoring) of SCNs, as rated by the staff nurses was related to their safety compliance scores. SCNs' own ratings of Envisioning change and Supporting behaviours were associated with patient infection rates, whereas only Recognising behaviours, as rated by the staff nurses, were related to safety performance data of the unit (patient injury severity rates) providing partial support for the third hypothesis. This may be explained by the nature of the items: The scales were designed to measure general leadership behaviours, as opposed to safety-specific behaviours. For example, for the change oriented behaviours, items do not directly assess behaviours related to changes to improve safety practices, for recognizing behaviours; praise is given for the general performance of the team members rather than for the use of safety procedures or having a good safety record. In this respect, including behaviours with a specific focus on safety might have produced different results.

Leading by example behaviours were not included in the study hypotheses. However, the interview study demonstrated the relevance of these behaviours within in the hospital ward. Therefore they were included in the questionnaire but no effect was found. Its lack of influence on safety-related outcomes might signal a mediating effect of identification with the leader (Ilies et al., 2005). The motivational mechanisms between leader behaviours and follower identification (Kark et al., 2003) might indicate that SCNs can be motivating only when staff nurses identify with the leader and in turn are influenced to follow her or him as an example. 
Overall, despite the fact that both the self ratings and the upward ratings of leadership descriptions of the SCNs failed to predict the majority of the safety outcomes, safety performance metrics were better predicted by SCNs' own ratings than by the staff nurses' upward ratings. The latter might indicate the existence of a mediating factor. For example safety climate at the group level has been shown to be a proximal factor of individual safety compliance and safety participation (Neal and Griffin, 2006). This might suggest that leaders at the group level influence safety through their impact on safety climate by their actions and expectations prioritising safety. Moreover, staffing levels have been found to have an impact on safety outcomes, such as reduced mortality rates (Stone et al., 2008), patient safety outcomes (e.g. infection) (Ausserhofer et al (2013) and team performance (Gil et al., 2005). Given the financial constraints in the NHS and other healthcare systems, staffing levels and the workload of the staff might now have strong impact on safety related outcomes. Future research should include the organizational and contextual factors as mediating variables and investigate their effects on safety outcomes in relation to SCNs' leadership behaviours. Furthermore, in the absence of adequate level of staffing, understanding how skilfully SCNs use effective leadership behaviours is necessary. The current study demonstrated the directive approach of SCNs when the situation was more demanding rather than delegating the responsibilities to staff nurses who are capable of achieving the tasks. This might hinder the staff nurses' learning of managerial skills. In the case of challenging tasks, when the magnitude of the risk associated with the task is perceived to be low, SCNs' taking a less active leadership role may facilitate staff nurse skill development and enhance reliable performance (Klein et al., 2006).

Finally, the psychometric properties of the MPS leadership scale (Yukl et al 2002) had not been previously established with nurses and it was not possible to test its factorial structure due to 
the small size. The interview study did indicate the suitability of this taxonomy and the next step should be validating the instrument with a nursing sample.

\section{Limitations}

The present study was subject to a number of limitations. First, the data were collected from only one hospital and therefore the results might not generalize to other healthcare settings. The ward leaders who volunteered might have been more engaged in safety-related initiatives and retained staff more favourable towards their leadership styles. The staff nurses might have been describing their SCNs based on a specific event or providing a more general evaluation of their leaders' behaviours. As has been suggested (Michel et al., 2011), additional methods, such as observations or diaries, should be considered to elicit leadership behaviours which might provide more accurate data. Moreover, due to the voluntary nature of the study, we cannot eliminate the potential threat of non-response bias. With minimal biodata collected, it was not possible to explore whether the characteristics of the individuals who responded were systematically different from the nurses who did not participate in the study. Other limitations were the small sample size and the nature of the safety performance data. The low frequency and variability of the adverse events within the wards, while a highly desirable state, make it more difficult to test for associations with these outcome variables.

Finally, SCNs' own descriptions of their leadership behaviours better predicted the safety performance metrics compared to staff nurses' upward ratings. This might have occurred due to the fact that SCNs were responsible for preparing the unit safety performance data which might be a potential confound in the results. For the future research, using different research methods (i.e. observations) to assess safety performance can provide more insights to explain the leader influences on achieving safety-related targets. 


\section{Practical implications}

Given recent investigations into failures in NHS hospitals that revealed significant deficits in the standard of leadership (Mid Staffordshire NHS - Healthcare Commission, 2009; Francis Report 2013), the above findings have a number of implications. Leadership programmes for SCNs should focus on a range of behaviours; including change processes. In a study of Canadian nurses from 21 long term healthcare organizations (Mullen and Kelloway, 2009), managers' safety attitudes, self-efficacy and the intentions to promote safety were significantly increased following a safety-specific leadership training programme. In addition, the employees' perceptions of safety climate and of their managers' safety-specific leadership were also improved.

The UK government have recently focussed on nursing leadership, proposing reductions in bureaucracy and calling for hourly ward rounds by the nurses (RCN, 2012). The findings on staff shortages reported by the SCNs endorse earlier reports (NHS Staff Survey, 2011). Investing resources (i.e. adequate staffing levels) to support senior charge nurses in their role as team leaders should be taken into consideration as part of any future action plan.

\section{Overall conclusion}

To conclude, this study provides preliminary data on the usability of a standard leadership taxonomy on a nursing sample. It revealed a set of leadership behaviours used in the SCN role and examined the link between these behaviours and wards' safety performance metrics for both staff and patients. Several task, relations and change oriented behaviours appeared to be associated with lower infection rates, patient safety incidents, and better safety compliance by 
staff. The findings, although preliminary, underline the importance of the ward leaders' role in achieving a high performing team in relation to safety. 


\section{References}

Agnew, C., Flin, R., \& Reid, J. (2012) Nurse leadership and patient safety. Editorial. British Medical Journal, 345.

Agnew, C., Flin, R., \& Mearns, K. (2013). Patient safety climate and worker safety behaviours in acute hospitals in Scotland. Journal of Safety Research, 45, 95-101.

Amabile, T., Schatzel, E., Moneta, G. \& Kramer, S. (2004) Leader behaviours and the work environment for creativity: Perceived leader support. Leadership Quarterly, 15, 5-32.

Anderson R., Issel L. \& McDaniel R. (2003) Nursing homes as complex adaptive systems. Nursing Research, 52, 12-21.

Ausserhof, D., Schubert, M., Desmedt, M., Blegen, M., De Geest, S. \& Schwendimann, R. (2013) The association of patient safety climate and nurse-related organizational factors with selected patient outcomes: A cross sectional survey. International Journal of Nursing Studies, 50, 240-252.

Avolio, B., Bass, B. \& Jung, D. (1999). Reexamining the components of transformational and transactional leadership using the Multifactor Leadership Questionnaire. Journal of Occupational and Organizational Psychology, 7, 441-462.

Barling, J., Loughlin, C., \& Kelloway, E. (2002). Development and test of a model linking transformational leadership and occupational safety. Journal of Applied Psychology, 87, 488-496.

Battilana J., Gilmartin M., Sengul M. et al. (2010). Leadership competences for implementing planned organizational change. Leadership Quarterly, 21, 422-438.

Bliese, P. (2000). Within-group agreement, non-independence, and reliability: implications for data aggregation and analysis. In K. Klein, \& S. Kozlowski (Eds.), Multi-level theory, research and methods in organizations: Foundations, extensions, and new directions (pp. 349-381). San Francisco, CA: Jossey-Bass.

Boyle S. (2004) Nursing unit characteristics and patient outcomes. Nursing Economics, 22, $111-123$.

Cairns, S., Murdoch, F. \& Blatchford, O. (2010). Quarterly report on the surveillance of Staphylococcus aureus bacteraemia (S. aureus bacteraemia) in Scotland October December 2009. HPS Weekly Report, 44, 132-140.

Chen, H., Beck, S., Amos, L. (2005). Leadership styles and nursing faculty job satisfaction in Taiwan. Journal of Nursing Scholarship, 37, 374-380.

Chiok Foong Loke, J. (2001). Leadership behaviours: effects on job satisfaction, productivity and organizational commitment. Journal of Nursing Management, 9, 191-204.

Clarke, S. (2006). The relationship between safety climate and safety performance: A metaanalytic review. Journal of Occupational Health Psychology, 11, 315-327. 
Costa, A. \& Anderson, N. (2001). Measuring trust in teams: development and validation of a multifaceted measure of formative and reflective indicators of team trust. European Journal of Work and Organizational Psychology, 20, 119-154.

Cronbach, L. (1951). Coefficient alpha and the internal structure of tests.

Psychometrika, 16, 297-334.

Cullen, J. \& Hammer, L. (2007). Developing and testing a theoretical model linking workfamily conflict to employee safety. Journal of Occupational Health Psychology, 12, 266278.

Cummings, G., MacGregor, T., Davey, M., Lee, H., Wong, C., Lo, A., et al. (2010). Leadership styles and outcome patterns for the nursing workforce and work environment: A systematic review. International Journal of Nursing Studies, 47, 363-385.

Cummings, G., 2004. Investing relational energy: the hallmark of resonant leadership. Canadian Journal of Nursing Leadership, 17, 76-87.

Denscombe, M., 2007. The Good Researcher Guide for Small-Scale Social Research Projects. Open University Press, Maidenhead, England.

Ellefsen, B. (1998). Influence and leadership in community-based nursing in Norway. Public Health Nursing, 15, 348-354.

Elo, S. \& Kynga, H. (2008). The qualitative content analysis process. Journal of Advanced Nursing 62(1), 107-115.

Flin R, Yule S (2004). Leadership for safety: industrial experience. Qual Saf Health Care;13 Suppl II:45-51

Fontana, A., \& Prey, J. (1998). Interviewing: The art of science. In N. K. Denzin \& Y. S. Lincoln (Eds.), Collectinga nd interpretingq ualitativem aterials (pp. 47-78). Thousand Oaks, CA: Sage.

Frederick, K., Mannion, R. \& Davies, H. (2011).Understanding culture and culture management in the English NHS: a comparison of professional and patient perspectives. Journal of Evaluation in Clinical Practice, 17, 111-117.

Germain, P. \& Cummings, G. (2010). The influence of nursing leadership on nurse performance: a systematic literature review. Journal of Nursing Management, 18, 425-439.

Gil F, Roman, R., Alcover, C. \& Barassa, A. (2005). Change-oriented leadership, satisfaction and performance in work groups: Effects of team climate and group potency. Journal of Managerial Psychology, 20, 312 - 328.

Guest G, Bunce A, \& Johnson L (2006). How many interviews are enough? An experiment with data saturation and variability. Field Methods, 18, 59-82. 
Hayes A, \& Krippendorff, K. (2007). Answering the call for a standard reliability measure for coding data. Communication Methods and Measures, 1, 77-89.

Havig, A., Skogstad, A., Veenstra, M. \& Romøren, T. (2011). The effects of leadership and ward factors on job satisfaction in nursing homes: a multilevel approach. Journal of Clinical Nursing, 20, 23-34.

Healthcare Commission (2005). Ward Staffing. London: Healthcare Commission.

Healthcare Commission (2009). Investigation into Mid Staffordshire NHS Foundation Trust. London: Commission for Healthcare Audit and Inspection.

Health Protection Scotland (2012). Emergence of Clostridium difficile ribotype 078 in Scotland. Retrieved from www.hps.scot.nhs.uk/haiic/sshaip/wrdetail.aspx?id=51657\&wrtype=2

Hendel, T., Fish, M., \& Galon, V. (2005). Leadership style and choice of strategy in conflict management among Israeli nurse managers in general hospitals. Journal of Nursing Management, 13, 137-146.

Houser J. (2003) A model for evaluating the context of nursing care delivery. Journal of Nursing Administration, 33, 39-47.

Ilies, R., Morgeson, F. P., \& Nahrgang, J. D. (2005). Authentic leadership and eudaemonic well-being: Understanding leader-follower outcomes. The Leadership Quarterly, 16, 373394

Institute of Medicine (2004). Keeping Patients Safe - Transforming the Work Environment of Nurses. National Academy Press, Washington, D.C.

Jones, M. \& Johnston, D. (2012) Does clinical incident seriousness and receipt of workbased support influence mood experienced by nurses at work? A behavioural diary study. International Journal of Nursing, 49, 978-987.

Judge, T., Piccolo, R. \& Ilies, R. (2004). The forgotten ones? The validity of consideration and initiating structure in leadership research. Journal of Applied Psychology, 89, 36-51.

Kark, R., Shamir, B., \& Chen, G. (2003). The two faces of transformational leadership: empowerment and dependency. Journal of Applied Psychology, 2, 246-255.

Kennedy, R. (2008). How do we get the managers we need and the leaders we want? A personal view. Journal of Nursing Management, 16, 942-945.

Kim, H. \& Yukl, G. (1995). Relationships of managerial effectiveness and advancement to self-reported and subordinate-reported leadership behaviors from the multiple-linkage mode. The Leadership Quarterly, 6, 361-377. 
Klein, K., Ziegert, J., Knight, A. et al. (2006). Dynamic delegation: shared, hierarchical, and deindividualized leadership in extreme action teams. Administrative Science Quarterly, $51,590-621$.

Krippendorff, K. (2004) Reliability in content analysis: Some common misconceptions and recommendations. Human Communication Research, 30, 411-433.

Kunzle B., Kolbe M., \& Grote G. (2010). Ensuring patient safety through effective leadership behaviour: a literature review. Safety Science, 48, 1-17.

Larrabee, J., Janney, M., Ostrow, C. et al. (2003). Predicting registered nurse job satisfaction and intent to leave. Journal of Nursing Administration, 33, 271-283.

Leape, L., Bates, D., Cullen, D., Cooper, J., Demonaco, H., Gallivan T, et al. (1995). Systems analysis of adverse drug events: ADE Prevention Study Group. Journal of American Medical Association, 274, 35-43.

Le Breton, J. \& Senter, J. (2008). Answers to 20 questions about interrater reliability and interrater agreement. Organizational Research Methods, 11, 815-852.

Mearns, K., Whitaker, S., \& Flin, R. (2003). Safety climate, safety management practice and safety performance in offshore environments. Safety Science, 41,641-680.

Michel, J., Lyons, B. \& Cho, J. (2011). Is the full-range model of leadership really a fullrange model of effective leader behavior? Journal of Leadership \& Organizational Studies, $18,493-507$.

Morrison, R., Jones, L., Fuller, B., 1997. The relation between leadership style and empowerment on job satisfaction of nurses. Journal of Nursing Administration 27, 27-34.

Mullen, J., \& Kelloway, E. (2009). Safety leadership: A longitudinal study of the effects of transformational leadership on safety outcomes. Journal of Occupational and Organizational Psychology, 82, 253-272.

Mullen, J., \& Kelloway, E. (2011). Occupational health and safety leadership. In J. Campbell Quick \& L.Tetrick (Eds.), Handbook of occupational health psychology (2nd ed., pp. 357-372). Washington, DC: American Psychological Association.

Neal, A., Griffin, M. \& Hart, P. (2000). The impact of organizational climate on safety climate and individual behaviour. Safety Science, 34, 99-109.

Neal, A., \& Griffin, M. (2006). A study of the lagged relationships among safety climate, safety motivation, safety behavior, and accidents at the individual and group levels. Journal of Applied Psychology, 91, 946-953.

Reader, T., Flin R. \& Cuthbertson, B. (2011). Team leadership in the intensive care unit: the perspective of specialists. Critical Care Medicine, 39,1683-1691. 
Royal College of Nursing (2009). Breaking down barriers, driving up standards. London: RCN.

Royal College of Nursing (2012). Staffing key to PM's quality drive, says RCN.

Retrieved from http://www.rcn.org.uk/newsevents/news/article/uk/staffing_key_to_ pms_quality_drive,_says_rcn.

Sellgren, S., Ekvall, G., Tomson, G., 2008. Leadership behaviour of nurse managers in relation to job satisfaction and work climate. Journal of Nursing Management 16, 578-587.

Stone, P., Pogorzelska, M., Knuches, L. \& Hirschhorn, L. (2008). Hospital staffing and health care-associated infections: A systematic review of the literature. Healthcare Epidemiology, 47, 937-944.

Stordeur, S., Vandenberghe, C., D'hoore, W., 2000. Leadership styles across hierarchical levels in nursing departments. Nursing Research, 49, 37-43.

Tabachnik, B. \& Fidell, L. (2007). Using multivariate statistics (5th ed.) Boston:Pearson.

Thomas, J. (2012) A Nurse's Survival Guide to Leadership and Management on the Ward. London: Churchill Livingstone.

Turner, N., Stride, C., Cartel, A., McCaughey' D. \& Carroll, A. (2012). Job demandscontrol-support model and employee safety performance. Accident Analysis \& Prevention, $45,811-817$.

Vincent C. (2006). Patient Safety. Edinburgh: Churchill Livingstone.

Wang, G., Oh, I., Courtright, S. \& Colbert, A. (2011) Transformational leadership and performance across criteria and levels: A meta-analytic review of 25 years of research. Group and Organization Management, 36, 223-270.

Wong, C. \& Cummings, G. (2007). The relationship between leadership and patient outcomes: a systematic review. Journal of Nursing Management, 15, 508-521.

Yukl, G., \& Mahsud, R. (2010). Why flexible and adaptive leadership is essential. Consulting Psychology Journal: Research \& Practice, 62, 81-93.

Yukl, G., O’Donnell, M. \& Taber, T. (2009). Influence of leader behaviours on the leadermember exchange relationship. Journal of Managerial Psychology, 24, 289-299.

Yukl, G. (2008). How leaders influence organizational effectiveness. Leadership Quarterly, 19, 708-722.

Yukl, G. (2006). Leadership in organizations (6th ed). Upper Saddle River: Prentice Hall.

Yukl, G., Gordon, A., Taber, T. (2002). A hierarchical taxonomy of leadership behavior: Integrating a half century of behavior research. Journal of Leadership \& Organizational Studies, 9, 15-32. 
Yukl, G. (1999a). An evaluation of conceptual weaknesses in transformational and charismatic leadership theories. Leadership Quarterly, 10, 285-305

Yukl, G. (1999b). An evaluative essay on current conceptions of effective leadership. European Journal of Work and Organizational Psychology, 8, 33-48.

Yukl, G. \& Van Fleet, D. (1982). Cross-situational, multi-method research on military leader effectiveness. Organizational Behavior and Human Performance, 30, 87-108.

Yun, S., Faraj, S., Henry, P. (2005). Contingent leadership and effectiveness of trauma resuscitation teams. Journal of Applied Psychology, 90, 1288-1296.

Zohar, D. (2000). A group-level model of safety climate: Testing the effect of group climate on micro-accidents in manufacturing jobs. Journal of Applied Psychology, $85,587-596$.

Zohar, D. (2002). The effects of leadership dimensions, safety climate, and assigned priorities on minor injuries in work groups. Journal of Organizational Behavior, 23, 75_92.

Zohar, D., \& Luria, G. (2004). Climate as a social- cognitive construction of supervisory safety practices: Scripts as proxy of behavior patterns. Journal of Applied Psychology, 89, $322-333$.

Zohar, D., Livne, Y., Tenne-Gazit O. et al. (2007). Healthcare climate: a framework for measuring and improving patient safety. Critical Care Medicine, 35, 1312-7. 